\title{
Comparative Study between Intralesional Injection of Vitamin D3 and Candida Albicans Antigen in Treatment of Plantar Warts
}

\author{
Mohamed Abd-Elmonem Abd-Elaal, Hassan Mamdouh Abd-Elaziz, Karim Atwa Ahmed
}

Department of Dermatology, Venereology and Andrology, Faculty of Medicine,

*Corresponding author: Karim Atwa Ahmed, E-mail: kaak_25@yahoo.com, Mobile: (+20) 01117501990 Al-Azhar University, Cairo, Egypt

\begin{abstract}
Background: Numerous therapeutic modalities have been used either singly or in combination to treat recalcitrant warts. However, a single treatment that is entirely effective in all patients is not yet explored. This might be attributed to the absence of specific antiviral medications against human papilloma virus (HPV) infection.

Objective: The aim of this work was to compare efficacy of intralesional vitamin D3 in treatment of plantar warts in comparison to candida albicans antigen.

Patients and methods: This study included a total of 40 patients suffering from plantar warts, attending at Dermatology and Andrology Outpatient Clinic, Dermatology Department, Al-Azhar University Hospitals. The included subjects were randomly divided into two groups; Group A (Candida antigen group) consisted of 20 patients, subjected to intralesional injection of candida albicans antigen and Group B: (Vitamin D3 group) consisted of 20 patients, subjected to intralesional injection of Vitamin D3.

Results: Results revealed that there were no statistically significant correlations between age, sex of patients, duration of treated warts and clinical response in both treatment groups. However, a statistically significant correlation existed between the number of treated warts and response in Vitamin D group. Complete response occurred in patients with low number of warts. At the end, our results showed that there was no statistically significant correlation in complete response between candida antigen and vitaminD3. Both treatments show comparable efficacy and safety in treatment of plantar warts.
\end{abstract}

Conclusion: Treatment of multiple warts by intralesional injection of candida antigen or vitamin D3 is safe and effective, with good cure rates, excellent safety profile and minimal recurrences.

Keywords: Vitamin D3, Candida Albicans antigen, Plantar warts.

\section{INTRODUCTION}

Warts are common epidermal growths caused by various strains of human papillomavirus (HPV) afflicting all age groups. They have an unsightly appearance and are mostly asymptomatic but sometimes may be painful, as in the case of palmoplantar warts ${ }^{(\mathbf{1})}$.

The virus initially targets the basal cells and undergoes a latent phase of slow replication. As the epidermis grows superficially, the virus induces hyperplasia and hyperkeratosis ${ }^{(1)}$.

Plantar warts are typically refractory to treatment, and multiple treatment sessions are required to clear lesions completely ${ }^{(2)}$.

Recalcitrant warts are resistant to conventional therapeutic options and, despite treatment, continue to increase in size and number ${ }^{(3)}$.

Warts are usually treated by traditional destructive modalities such as cryotherapy, electrocoagulation, topical salicylic acid, topical 5-fluorouracil, and laser surgery. All of these treatment options can be painful, time consuming, and/or expensive, and none is considered the gold standard ${ }^{(4)}$.

Treatments for warts have included intralesional injections of tuberculin purified protein derivative (PPD); measles, mumps, and rubella (MMR) vaccine; Mycobacterium vaccine and Candida albicans antigen (5).

While the mechanisms of vaccine and antigen therapy have not been elucidated, it is thought that the host immune system is activated to recognize the virus, leading to wart clearance. This treatment approach is known as intralesional immunotherapy. Topical vitamin $\mathrm{D}$ has been used successfully for wart treatment in some cases ${ }^{(\boldsymbol{6})}$.

The effect of vitamin $\mathrm{D}$ derivatives on warts is speculated to be derived from its potential to regulate epidermal cell proliferation and differentiation and to modulate cytokine production ${ }^{(7)}$.

Upregulation of vitamin D receptors in the skin leads to the induction of antimicrobial peptide expression ${ }^{(\mathbf{8})}$.

Candida antigen is made from the culture filtrate and cells of two strains of Candida albicans. It is indicated in origin for use as a recall antigen for detecting delayed-type hypersensitivity by intracutaneous (intradermal) testing, the inflammatory response associated with the DTH reaction is characterized by an infiltration of lymphocytes and macrophages at the site of antigen deposition. Specific cell types that appear to play a major role in the DTH response include CD4 and CD8 T lymphocytes ${ }^{(9)}$.

The aim of this work was to compare efficacy of intralesional vitamin D3 in treatment of plantar warts in comparison to candida albicans antigen.

\section{PATIENTS AND METHODS}

This study included a total of 40 patients suffering from plantar warts, attending at Dermatology and Andrology Outpatient Clinic, Dermatology Department, Al-Azhar University Hospitals. 
Ethical approval and written informed consent: Approval of the ethical committee was obtained from Al-Azhar University Academic And Ethical Committee. Written informed consent from all the subjects were obtained.

All patients were subjected to: Complete history taking, general and dermatological, examination, identifying number of lesions, taking photos for the lesions at first visit and follow up visits.

\section{Inclusion criteria:}

- Patients above 18 years old.

- Both males and females.

- Patients with recurrent plantar warts or not responding to conventional lines like cryotherapy and topical salicylic acid.

Exclusion criteria:

- Pregnant or breast feeding females.

- Acute febrile illness.

- Known hypersensitivity to Candida antigen or vitamin D3.

- Patients who receiving other treatments for warts or received any treatment in the last month.

- Iatrogenic or primary immuno-suppression.

The included subjects were randomly divided into two groups; Group A (Candida antigen group) consisted of 20 patients, subjected to intralesional injection of $0.1 \mathrm{ml}$ of Candida antigen in the oldest and almost largest wart (Mother Wart). Injection was done every 3 weeks until clearance of lesions or maximum of 3 treatments. Group B: (Vitamin D3 group) consisted of 20 patients, subjected to intralesional injection of Vitamin D3. Initially, each lesion was injected with $0.1 \mathrm{~mL}$ of lidocaine. A few minutes later, $0.2 \mathrm{~mL}$ of vitamin D3 $(7.5 \mathrm{mg} / \mathrm{mL})$ solution was slowly injected into the base of each wart using a 21-gauge syringe. A maximum of 5 warts was treated per patient in 1 session. The maximum total amount of vitamin D3 injected into a patient in 1 session was $7.5 \mathrm{mg}$. Injections was done every 3 weeks until clearance of lesions or maximum of 3 treatments. Follow-up of patients was done every 4 weeks for 3 months to detect any recurrence.

Note: Before treatment of group A, patients were tested for existing immunity for candida antigen by intradermal injection of $0.1 \mathrm{ml}$ candida antigen $(1 / 100)$ in the forearm. The result appeared in 48-72 hours by erythema and induration more than $0.5 \mathrm{~cm}$ at the site of injection. Negative patients were excluded from the study. Positive patients started treatment with intralesional injection.

\section{Evaluation:}

The results were evaluated by clinical response of lesions as follows:

- Complete response: total clearance of wart.

- Partial resolution: noticeable improvement but not full clearance.

- No response: absolutely no improvement.

Resolution of distant untreated warts was also assessed. Immediate and late adverse effects were evaluated after each treatment session.

\section{Statistical analysis}

Data were analyzed using Statistical Program for Social Science (SPSS) version 15.0. Quantitative data were expressed as mean \pm standard deviation (SD). Qualitative data were expressed as frequency and percentage.

The following tests were done:

Independent-samples t-test of significance: was used when comparing between two means.

Chi-square test: was used when comparing between non-parametric data.

Probability (P-value)

- P-value $<0.05$ was considered significant.

- P-value $<0.001$ was considered as highly significant.

- P-value > 0.05 was considered insignificant.

\section{RESULTS}

Table (1) shows that the mean age in candida group was $31.9 \pm 9.7$ years while it was $30.4 \pm 8.6$ years in Vit. $\mathrm{D}$ group $(\mathrm{p}$-value $=0.585)$. Male /female ratio are equal in both groups. Table (1).

Table (1): Comparison between studied groups as regard age and sex.

\begin{tabular}{|c|c|c|c|c|}
\hline \multicolumn{2}{|l|}{ Variables } & $\begin{array}{l}\text { Candida } \\
(\mathrm{N}=\mathbf{2 0})\end{array}$ & $\begin{array}{l}\text { Vit. D } \\
(\mathrm{N}=\mathbf{2 0})\end{array}$ & P-value \\
\hline \multirow{2}{*}{ Age (years) } & Mean & 31.9 & 30.4 & \multirow{2}{*}{0.585} \\
\hline & \pm SD & 9.7 & 8.6 & \\
\hline \multirow{2}{*}{$\operatorname{Sex}(n, \%)$} & Male & $10(50 \%)$ & $10(50 \%)$ & \multirow{2}{*}{1.0} \\
\hline & Female & $10(50 \%)$ & $10(50 \%)$ & \\
\hline
\end{tabular}

This table shows no statistically significant difference (p-value $>\mathbf{0 . 0 5}$ ) between studied groups as regard age and sex.

Table (2): comparison between studied groups as regard side effects. 


\begin{tabular}{|c|c|c|c|c|}
\hline \multicolumn{2}{|c|}{ Variables } & $\begin{array}{l}\text { Candida } \\
(\mathbf{N}=20)\end{array}$ & $\begin{array}{l}\text { Vit. } D \\
(N=20)\end{array}$ & P-value \\
\hline \multirow{4}{*}{ 胥 } & No & $8(40 \%)$ & $12(60 \%)$ & \multirow{4}{*}{$0.002 * *$} \\
\hline & Pain & $2(10 \%)$ & $8(40 \%)$ & \\
\hline & Flu like symptoms & $5(25 \%)$ & $0(0 \%)$ & \\
\hline & Pain, Erythema \& edema & $5(25 \%)$ & $0(0 \%)$ & \\
\hline
\end{tabular}

**: p-value $<0.05$ is considered significant.

Table (2) shows statistically significant difference $(\mathbf{p}$-value $<\mathbf{0 . 0 5})$ between studied groups as regard side effects.

Table (3): comparison between studied groups as regard number of injections.

\begin{tabular}{|l|l|l|l|l|}
\hline \multicolumn{2}{|l|}{ Variables } & $\begin{array}{l}\text { Candida } \\
(\mathbf{N}=\mathbf{2 0})\end{array}$ & $\begin{array}{l}\text { Vit. D } \\
(\mathbf{N = 2 0})\end{array}$ & P-value \\
\hline \multirow{2}{*}{ Number of injections } & Mean & 2.6 & 2.5 & \multirow{2}{*}{0.809} \\
\cline { 2 - 5 } & $\mathbf{\pm S D}$ & 0.6 & 0.7 & \\
\hline
\end{tabular}

Table (3) shows no statistically significant difference (p-value $>\mathbf{0 . 0 5}$ ) between studied groups as regard number of injections. The mean number of injections in candida group was $2.6 \pm 0.6$ while it was $2.5 \pm 0.7$ in Vit. $\mathrm{D}$ group $(\mathrm{p}$-value $=0.809)$.

Table (4): comparison between studied groups as regard recurrence.

\begin{tabular}{|l|l|l|l|l|}
\hline \multirow{2}{*}{ Variables } & $\begin{array}{l}\text { Candida } \\
(\mathbf{N}=\mathbf{9})\end{array}$ & $\begin{array}{l}\text { Vit. D } \\
(\mathbf{N = 8 )}\end{array}$ & \multirow{2}{*}{ P-value } \\
\hline \multirow{2}{*}{ Recurrence } & Yes & $1(11.1 \%)$ & $1(12.5 \%)$ & \multirow{2}{*}{0.929} \\
\cline { 2 - 5 } & No & $8(88.9 \%)$ & $7(87.5 \%)$ & \\
\hline
\end{tabular}

Table (4) shows no statistical significant difference (p-value $>\mathbf{0 . 0 5}$ ) between studied groups as regard recurrence.

Table (5): comparison between studied groups as regard response of all warts.

\begin{tabular}{|l|l|l|l|l|}
\hline \multirow{2}{|l|}{ Variables } & $\begin{array}{l}\text { Candida } \\
(\mathbf{N = 2 0 )}\end{array}$ & $\begin{array}{l}\text { Vit. D } \\
(\mathbf{N = 2 0})\end{array}$ & \multirow{2}{*}{ P-value } \\
\hline \multirow{3}{*}{ Response of all warts } & Complete & $9(45 \%)$ & $8(40 \%)$ & \multirow{3}{*}{0.928} \\
\cline { 2 - 4 } & Partial & $6(30 \%)$ & $6(35 \%)$ & \\
\cline { 2 - 4 } & No & $5(25 \%)$ & $6(35 \%)$ & \\
\hline
\end{tabular}

Table (5) shows no statistical significant difference (p-value $>\mathbf{0 . 0 5}$ ) between studied groups as regard response of all warts.

Table (6): Relation between age and response in studied groups.

\begin{tabular}{|l|l|l|l|l|l|}
\hline \multirow{2}{*}{ Variables } & Complete & Partial & No & \multirow{2}{*}{ P-value } \\
\hline \multirow{2}{*}{ Age in candida group } & Mean & 30.9 & 36.2 & 28.8 & \multirow{2}{*}{0.437} \\
\cline { 2 - 6 } & $\mathbf{\pm S D}$ & 9.04 & 12.8 & 5.9 & \multirow{2}{*}{0.44} \\
\hline \multirow{2}{*}{ Age in Vit. D group } & Mean & 32.4 & 31.5 & 26.5 & \\
\cline { 2 - 6 } & $\mathbf{\pm S D}$ & 5.2 & 11.7 & 8.8 & \\
\hline p-value & 0.68 & 0.52 & 0.61 & \\
\hline
\end{tabular}

Table (6) shows shows no statistical significant (p-value $>\mathbf{0 . 0 5}$ ) relation between age and response in studied groups.

Table (7): Relation between duration and response in studied groups.

\begin{tabular}{|l|l|l|l|l|l|}
\hline Variables & Complete & Partial & No & \multirow{2}{*}{ P-value } \\
\hline \multirow{2}{*}{ Duration in candida group } & Mean & 3.8 & 4.8 & 4.6 & \multirow{2}{*}{0.456} \\
\cline { 2 - 6 } & $\mathbf{\pm S D}$ & 1.3 & 2.2 & 1.5 & \\
\hline \multirow{2}{*}{ Duration in Vit. D group } & Mean & 4.1 & 4.3 & 4.8 & \multirow{2}{*}{0.732} \\
\cline { 2 - 7 } & $\mathbf{\pm S D}$ & 1.1 & 1.4 & 2.4 & \\
\hline \multirow{2}{*}{ p-value } & 0.61 & 0.64 & 0.87 & \\
\hline
\end{tabular}

Table (7) shows shows no statistical significant (p-value $>\mathbf{0 . 0 5}$ ) relation between duration and response in studied groups. 
Table (8): Relation between number and response in studied groups.

\begin{tabular}{|c|c|c|c|c|c|}
\hline \multicolumn{2}{|l|}{ Variables } & Complete & Partial & No & P-value \\
\hline \multirow{2}{*}{$\begin{array}{l}\text { Number in candida } \\
\text { group }\end{array}$} & Mean & 2.6 & 2.7 & 2.4 & \multirow{2}{*}{0.924} \\
\hline & $\pm \mathrm{SD}$ & 1.3 & 0.8 & 0.9 & \\
\hline \multirow{2}{*}{$\begin{array}{l}\text { Number in Vit. D } \\
\text { group }\end{array}$} & Mean & 1.6 & 2.3 & 2.8 & \multirow{2}{*}{0.048 *** } \\
\hline & $\pm \mathrm{SD}$ & 0.7 & 1.03 & 0.8 & \\
\hline \multicolumn{2}{|l|}{ p-value } & 0.071 & 0.47 & 0.46 & \\
\hline
\end{tabular}

Table (8) shows shows

- No statistical significant (p-value $>\mathbf{0 . 0 5}$ ) relation between number and response in candida group.

- Statistically significant (p-value $<\mathbf{0 . 0 5}$ ) relation between number and response in Vit. D group. Complete response occurs in patients with low number of warts $(1.6 \pm 0.7)$.

Table (9): Relation between sex and response in studied groups.

\begin{tabular}{|l|l|l|l|l|l|}
\hline \multirow{2}{*}{ Variables } & Complete & Partial & No & \multirow{2}{*}{ P-value } \\
\hline \multirow{2}{*}{$\begin{array}{l}\text { Sex in candida } \\
\text { group }\end{array}$} & Male & $4(44.4 \%)$ & $2(33.3 \%)$ & $4(80 \%)$ & \multirow{2}{*}{0.276} \\
\cline { 2 - 5 } \multirow{2}{*}{ Sex in Vit. D group } & Female & $5(55.6 \%)$ & $4(66.7 \%)$ & $1(20 \%)$ & \multirow{2}{*}{0.097} \\
\cline { 2 - 5 } & Male & $6(75 \%)$ & $1(16.7 \%)$ & $3(50 \%)$ & $3(50 \%)$ \\
\cline { 2 - 5 } p-value & Female & $2(25 \%)$ & $5(83.3 \%)$ & 0.3 & \\
\hline
\end{tabular}

Table (9) shows shows no statistical significant (p-value $>\mathbf{0 . 0 5}$ ) relation between sex and response in studied groups.

Candida antigen patients before and after treatment:

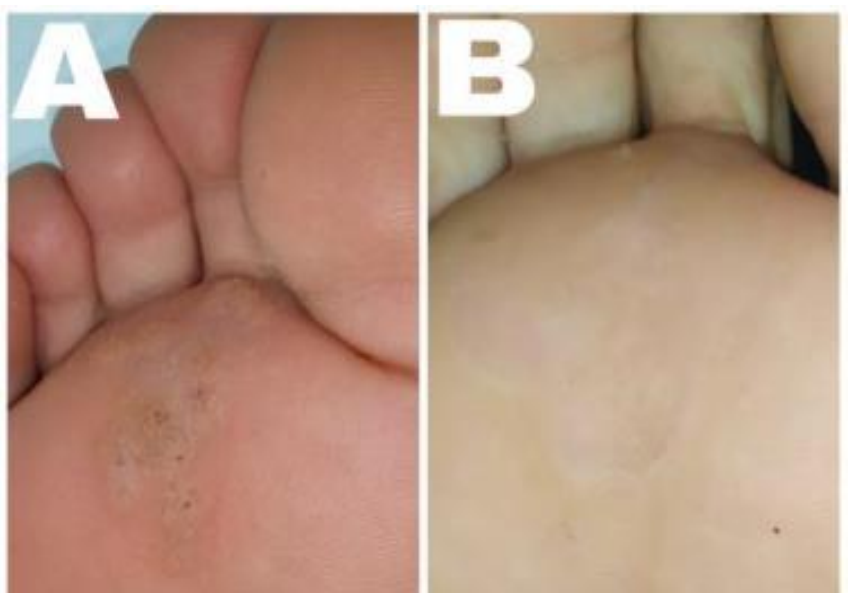

Fig. (1): (A) Before (B) After

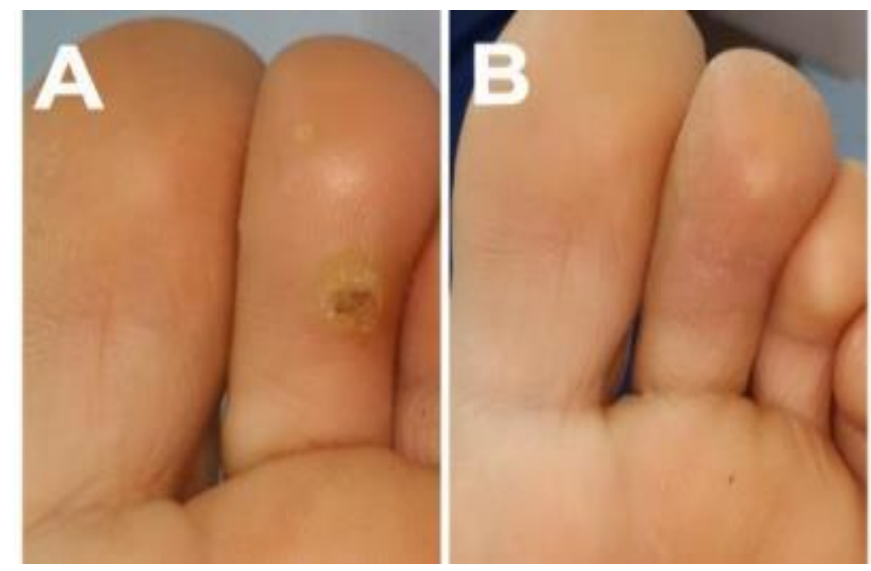

Fig. (2): (A) Before (B) After

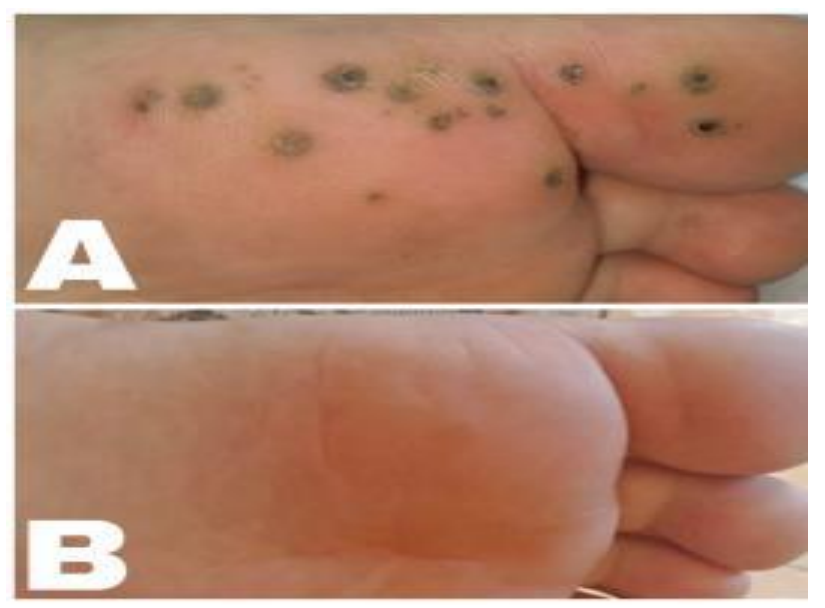

Fig. (3): (A) Before (B) After

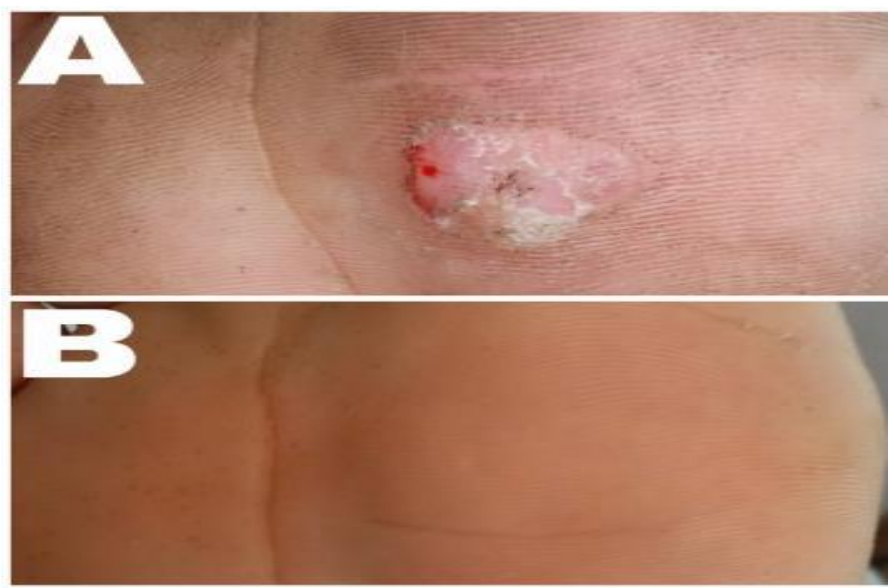

Fig. (4): (A) Before (B) After DISCUSSION 
The aim of the current work was to compare safety and efficacy of intralesional vitamin D3 and candida albicans antigen in treatment of plantar warts. Patients randomized into 2 groups, group A (candida antigen) and group B (vitamin D3).

For vitamin D3 group, our study showed that of 20 patients received intralesional vitamin D3 there were 8 patients showed complete response (40\%), 6 patients showed partial response (30\%) and 6 patients showed no response $(30 \%)$.

vitamin D used in treatment of wart either topical or intralesional. Egawa and Ono ${ }^{(10)}$ treated three immunocompromised patients with recalcitrant warts successfully and safely with a vitamin D3 derivative using a half-day occlusive dressing technique (ODT). Imagawa and Suzuki (11) successfully treated 17 patients with recalcitrant warts with topical vitamin D3 derivative (maxacalcitol, 1 $\alpha$, 25-dihydroxy-22oxacalcitriol). Treatment of wart with intralesional vitamin D3 used by Aktas et al. ${ }^{(12)}$ for plantar warts who reported that 16 of 20 patients $(80 \%)$ showed complete resolution of warts, 1 patient showed partial resolution and three patients failed to show any response. Raghukumar et al. ${ }^{(13)}$ also used intralesional vitamin D3 injection in the treatment of recalcitrant warts on sixty patients with complete response was seen in 54 of 60 (90\%), partial response in 4 of 60 (6.66\%), and no response in 2 of $60(3.33 \%)$. With complete resolution of distant warts was noticed in all patients.

Vitamin D3 was compared with purified protein derivative (PPD) by Singh et al. ${ }^{(14)}$. A total of 80 patients were included in the study. Group 1 patients were injected with PPD intralesional while in group 2 patients were injected vitamin D3. In group 1 a total of $80 \%$ (32 patients) showed complete clearance and 20\% (8 patients) showed partial response while in group 2 $72.5 \%$ (29 patients) showed complete clearance while $27.5 \%$ (11 patients) showed partial response. Also there was a study by Fathy $\boldsymbol{e t}$ al. ${ }^{(15)}$ on 60 patients who were divided into three groups: Group I received intralesional vitamin D3, Group II intralesional Candida antigen, and Group III intralesional saline (control group). According to the grade of response in Group I, 70\% showed excellent response and 30\% were nonresponders. In Group II, 25\% showed excellent response, $5 \%$ showed very good response, $15 \%$ showed good response, and $20 \%$ were nonresponders. In Group III, $100 \%$ of cases were nonresponders.

The exact mechanism of vitamin D activity against warts remains to be elucidated; however, it controls cell proliferation and differentiation and has immuneregulatory activities. Its effects are mediated via the vitamin $\mathrm{D}$ receptor (VDR), which is present in keratinocytes, melanocytes, fibroblasts, and immune system cells of the skin (2). It was observed that there is toll-like receptor activation of human macrophages which upregulated the expression of VDR and vitamin D-1-hydroxylase genes, leading to induction of the antimicrobial peptide ${ }^{(\mathbf{1 6})}$.

The effects of vitamin D injection in treating warts still not completely understood; however it acts through controlling cell proliferation and differentiation via up regulation of vitamin $\mathrm{D}$ receptors on keratinocytes and immune system cells of the skin that leads to the activation of toll like receptors of human macrophages and induction of antimicrobial peptides expression as thymic stromal, lymphopoietin and cathelicidin. It also reduces the synthesis of IL 1a and IL6 resulting in decreased inflammation ${ }^{(6)}$.

In our study according to candida antigen group, complete response occurred in 11 patients $(55 \%)$ of injected warts and $(41 \%)$ in distal warts and partial response in $(20 \%)$ of injected warts and (18\%) in distal warts. From the 11 patients with complete response of injected warts, 2 patients have no distal warts and 2 have partial response for distal warts. For all warts complete cure occurred in 9 patients (45\%), partial response in 6 patients (30\%) and no response in 5 patients $(25 \%)$.

In many studies, intralesional candida antigen was used for treatment of warts. Phillips et al. ${ }^{(17)}$ reported that 73 patients $(70 \%)$ had complete cure within 8 weeks of the last injection.

Using intralesional candida antigen in children. Maronn et al. ${ }^{(18)}$ reported that $48 / 55$ (87\%) had complete resolution, 3/55 (6\%) had partial clearing, and $4 / 55$ (7\%) had no improvement. And added that the clearance rate may be overestimated, as many patients were also treated concurrently with liquid nitrogen or other therapies. Also, in study by Alikhan et al. ${ }^{(19)}$ on 100 patients, 20 patients had no response to the injections, 39 had a complete response and 41 had a partial response. And of the 41 patients with partial response, the injected wart cleared in 15 , did not clear in 25 , and response was not recorded in 1 patient.

Another study on multiple recalcitrant warts by Nofal et al. ${ }^{(20)}$ showed that from 36 patients received intralesional candida antigen 12 patients (33.3\%) showed complete clearance.

Patients in our study were followed for 12 weeks from the last session and recurrence was observed in one patient only $1 / 8(12.5 \%)$ in vitamin $\mathrm{D}$ group. In comparison to other studies Aktas et al. ${ }^{(12)}$ reported that there were no recurrences, Raghukumar et al. (13) reported 2 cases (3.3\%), Kavya et al. $^{(21)}$ reported 1 case (3\%) and Fathy et al. ${ }^{(15)}$ reported 1 case (5\%).

In candida group recurrence was observed in one case 1/9 (11.1\%) in comparison to Majid and Imran ${ }^{(22)}$ and Nofal et al. ${ }^{(20)}$ who reported that there were no recurrences. 
Regarding side effects pain at site of injection was the most reported side effect in both groups (18/40 patients). Also erythema, edema and flue like symptoms were noted.

Pain was more evident with vitamin D group (12/20 patients). And no other systemic or local reactions noted.

This is consistent with Raghukumar et al. ${ }^{(\mathbf{1 3})}$ who reported that all patients had transient mild to moderate pain at the time of injection. Two (3.33\%) patients developed edema at the site of injection, resolving within 1 week. Mild erythema was seen in $3(5 \%)$ patients. No signs of hypervitaminosis D or systemic side effects were seen in any patient.

With candida antigen injection the most annoying symptom for patients was flu-like symptoms (5 patients) which is consistent with Phillips et al. ${ }^{(17)}$ who reported that the majority of reactions reported in his study were consistent with local reactions but there were two patients who reported potential systemic side effects (body aches and fever) that were mild and transient symptoms.

Majid and Imran ${ }^{(22)}$ reported that pain at the injection site was the commonest adverse effect reported and this was reported by majority of the patients. The pain occurred at the time of injection only and was the most severe in intensity when the fingers were injected. Fever or myalgias was reported by three patients only and none of them required any analgesics or antipyretics for this purpose.

Adverse events also reported by Alikhan $\boldsymbol{e t}$ al. ${ }^{(19)}$ that were minimal, consisting primarily of local reactions like pain, blistering and swelling; one patient experienced flu-like symptoms and one experienced shakiness/ uneasiness, possibly due to a systemic immune response to the Candida antigen. Though the product is an allergen, anaphylaxis has not yet been reported for its use in warts, though one of patients had mild self-limited wheezing.

Other side effects reported in literature and didn't occur in our study were painful purple digit syndrome by Perman et al. ${ }^{(23)}$ and localized depigmentation by Wilmer et al. ${ }^{\text {(24) }}$.

Also our results revealed that there were no statistically significant correlations between age, sex of patients, duration of treated warts and clinical response in both treatment groups.

However, a statistically significant correlation existed between the number of treated warts and response in Vitamin D group. Complete response occurred in patients with low number of warts.

At the end, our results showed that there was no statistically significant correlation in complete response 6. , Kim CW and Kim SS (2015): Preliminary study of intralesional bleomycin injection for the treatment of genital warts. Ann Dermatol., 27:239-241. between candida antigen and vitaminD3. Both treatments show comparable efficacy and safety in treatment of plantar warts.

Some limitations to our study including small number of population and lack of control group matched for age, sex and duration.

\section{CONCLUSION}

Treatment of multiple warts by intralesional injection of candida antigen or vitamin D3 is safe and effective, with good cure rates, excellent safety profile and minimal recurrences.

Intralesional injection of candida antigen or vitamin D3 may be associated with better compliance and improvement of quality of life for many patients. Most wart treatment modalities are painful, need multiple visits (time and money consuming) and are directed to each individual wart. Accordingly, to have few injections, to be able to immediately resume normal daily activities, to have clearance of remote untreated warts and to be free of disfiguring scars, vitamin D3 or candida antigen were very much appreciated by all patients who were ready to repeat the treatment when needed.

\section{RECOMMENDATIONS}

Larger case-control studies as well as in vivo and in vitro studies are needed to elucidate the exact mechanism of action of vitamin D3 and establish the best dose, frequency and number of sessions needed to achieve the best response. In addition, Further studies for assessment of synergistic effect of using vitamin D3 and candida antigen in treating warts also recommended.

\section{REFERENCES}

1. Aldahan AS, Mlacker S, Shah VV, Kamath P, Alsaidan M, Samarkandy $S$ and Nouri K (2016): Efficacy of intralesional immunotherapy for the treatment of warts. A review of the literature. Dermatol Ther., 29(3):197-207.

2. AIGhamdi KM and Khurram H (2011): Successful treatment of periungual warts with diluted bleomycin using translesional multipuncture technique: a pilot prospective study. Dermatol Surg., 37(4):486-92.

3. Faghihi G, Vali A, Radan M, Eslamieh $G$ and Tajammoli $S$ (2010): Double-blind, randomized trials of local formic acid puncture technique in the treatment of common warts. Skinmed., 8(2):70-71.

4. Kimura U, Takeuchi K, Kinoshita A, Takamori K and Suga Y (2014): Long-pulsed 1064-nm neodymium:yttrium-aluminum-garnet laser treatment for refractory warts on hands and feet. J Dermatol., 41(3):252-257.

5. Lee JY

7. Moscarelli L, Annunziata F, Mjeshtri A, Paudice N, Tsalouchos A, Zanazzi $M$ and Bertoni $E$ (2011): Successful treatment of refractory wart with a topical 
activated vitamin $\mathrm{d}$ in a renal transplant recipient. Case Rep Transplant., 2011: 368623.

8. Rind T, Oiso N and Kawada A (2010): Successful treatment of anogenital wart with a topical vitamin $\mathrm{D}_{3}$ derivative in an infant. Case Rep Dermatol., 2:46-49.

9. AlGhamdi K, Kumar A and Moussa N (2013): The role of vitamin $\mathrm{D}$ in melanogenesis with an emphasis on vitiligo. Indian J Dermatol Venereol Leprol., 79(6):750758.

10.Paul WE (1993): Fundamental Immunology 3rd Ed., Raven Press, New York, Pp. 75-76.

11.Egawa $K$ and Ono $T$ (2004): Topical vitamin $D_{3}$ derivatives for recalcitrant warts in three immunocompromised patients. $\mathrm{Br} \mathrm{J}$ Dermatol., 150(2):374-376.

12. Imagawa I and Suzuki H (2007): Successful treatment of refractory warts with topical vitamin D3 derivative (maxacalcitol, 1alpha, 25-dihydroxy-22-oxacalcitriol) in 17 patients. J Dermatol., 34(4):264-266.

13. Aktas H, Ergin C, Demir B and Ekiz O (2015): Intralesional Vitamin D Injection May Be an Effective Treatment Option for Warts. Journal of Cutaneous Medicine and Surgery, 20(2): 118-122.

14. Raghukumar S, Ravikumar B, Vinay N, Suresh M, Aggarwal $A$ and Yashovardhana D (2017): Intralesional Vitamin $\mathrm{D}_{3}$ Injection in the Treatment of Recalcitrant Warts: A Novel Proposition. Journal of Cutaneous Medicine and Surgery, 21(4):320-324.

15.Singh SK, Mohan A, Gupta AK, and Pandey AK (2018): A comparative study between intralesional PPD and vitamin D3 in treatment of viral warts. International Journal of Research in Dermatology, 4: 197-201.

16. Fathy G, Sharara MA and Khafagy AH (2019): Intralesional vitamin D3 versus Candida antigen immunotherapy in the treatment of multiple recalcitrant plantar warts: A comparative case-control study. Dermatologic Therapy, e12997. https://www.ncbi.nlm.nih.gov/pubmed/31225688

17. Liu PT, Stenger S, Li H, Wenzel L et al. (2006): Tolllike receptor triggering of a vitamin D-mediated human antimicrobial response. Science, 311(5768):1770-1773.

18. Phillips RC, Ruhl TS, Pfenninger JL and Garber MR (2000): Treatment of warts with Candida antigen injection. Arch Dermatol., 136: 1274-1275.

19. Maronn M, Salm C, Lyon V and Galbraith S (2008): One-year experience with Candida antigen immunotherapy for warts and molluscum. Pediatr Dermatol., 25: 189-192.

20.Alikhan A, Griffin J and Newman C (2015): Use of Candida antigen injections for the treatment of verruca vulgaris: A two-year mayo clinic experience. J Dermatolog Treat., 11: 1-4.

21. Nofal A, Khattab F, Nofal E and Elgohary A (2018): Combined acitretin and Candida antigen versus either agent alone in the treatment of recalcitrant warts. J Am Acad Dermatol., 79(2):377-378.

22. Kavya M, Shashikumar BM, Harish MR and Shweta BP (2017): Safety and efficacy of intralesional vitamin D3 in cutaneous warts: An open uncontrolled trial. J Cutan Aesthet Surg., 10:90-94.

23. Majid I and Imran S (2013): Immunotherapy with intralesional Candida albicans antigen in resistant or recurrent warts: A study. Indian J Dermtol., 58:360-365.

24. Perman M, Sterling JB \& Gaspari A (2005): The painful purple digit: An alarming complication of Candida albicans antigen treatment of recalcitrant warts. Dermatitis, 16: 38-40.

25. Wilmer EN, Burkhart CN and Morrell DS (2013): Goodbye warts, hello vitiligo: Candida antigen-induced depigmentation. Pediat Dermatol., 30:214-15. 